\title{
Alternative adsorbent materials for application in industrial processes
}

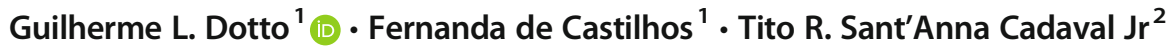

Received: 7 August 2019 / Accepted: 16 August 2019 / Published online: 31 August 2019

(C) Springer-Verlag GmbH Germany, part of Springer Nature 2019

This special issue of Environmental Science and Pollution Research highlights selected papers presented at the 12th Adsorption Brazilian Meeting (EBA 2018), held on April 23-25, 2018, in Gramado-RS, Brazil. This is a traditional meeting that occurs since 1996, and it was realized for the first time at the Rio Grande do Sul state. The organization of EBA 12 was carried out by the Federal University of Santa Maria (UFSM) with help of Federal University of Rio Grande do Sul (UFRGS), Federal University of Rio Grande (FURG), and University of Passo Fundo (UPF).

Around 400 professionals and students from the scientific, academic, and industrial areas have participated from EBA 12, to discuss topics like nanoporous adsorbents, environmental applications, processes, biotechnology, modeling and simulation, fundaments, and synthesis and characterization of adsorbents, petroleum, and natural gas. Important international researchers and speakers including Prof. Alírio Rodrigues (Portugal), Manuel Karim Sapag (Argentina), Jacques Desbrières (France), Ádrian Bonilla-Petriciolet (Mexico), and César Costapinto Santana (Brazil) have participated in EBA 12. The main attractions of EBA 12 were plenary conferences, keynotes, the traditional "Adsorption School," oral and poster presentations. The

Responsible editor: Philippe Garrigues

Guilherme L. Dotto

guilherme_dotto@yahoo.com.br

Fernanda de Castilhos

fernanda.castilhos@ufsm.br

Tito R. Sant'Anna Cadaval, Jr titoeq@gmail.com

1 Chemical Engineering Department, Federal University of Santa Maria, UFSM, Roraima Avenue, 1000, Santa Maria, RS 97105-900, Brazil

2 School of Chemistry and Food, Federal University of Rio GrandeFURG, km 8 Italia Avenue, Rio Grande, RS 96203-900, Brazil results were published in 313 articles, being the best papers selected for this special issue.

Finally, the main objectives of this meeting were attained as follows: the largest number of participants was reached and works of all editions were presented; an increase of the works in terms of quality and quantity was obtained. Therefore, the organizing committee of EBA 12 deeply thanks the Brazilian adsorption community, who came to Gramado to present the advances in their researches. We express our deep gratitude to all members of Organizing and Scientific Committees for their commitment, contribution, and time towards making the 12th Adsorption Brazilian Meeting a great success. We would like to extend our appreciation to contributing authors, reviewers, and Editorial Board of Environmental Science and Pollution Research for their excellent work in making this special issue possible.

Publisher's note Springer Nature remains neutral with regard to jurisdictional claims in published maps and institutional affiliations.

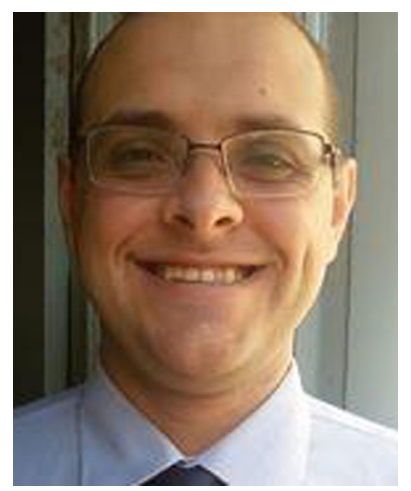

Guilherme Luiz Dotto is a professor in the Chemical Engineering Department at Federal University of Santa Maria (UFSM) and a permanent member of the Chemical Engineering post-graduation program and also of the Chemistry post-graduation program. His research is focused on the following areas: transport phenomena, unit operations, wastewater treatment, physicochemical treatments for wastewater, and separation processes. In these research areas, he has more than 170 published articles and also is a reviewer of more than 100 international journals. His H-index is 27. Prof. Dotto is an Editor of the Journal of Environmental Chemical Engineering and an Editorial board member of Environmental Science and Pollution Research. 


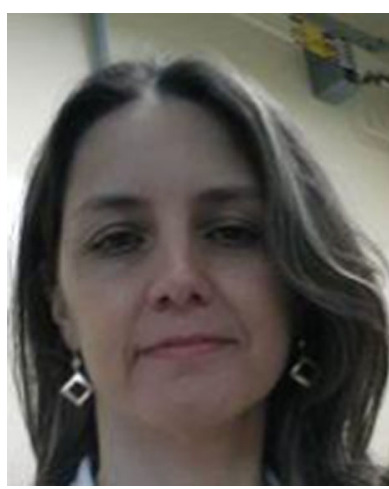

Fernanda de Castilhos is a chemical engineer (2000) from Maringá State University (Brazil), with $\mathrm{PhD}$ in Chemical Engineering (2004) from the same university. She has been a CNPq Research Productivity Scholar since 2009 and has published around 65 articles in several journals. She has supervised 24 master dissertations and 9 doctoral theses and has approved several research projects by funding agencies. She is a reviewer of 17 international journals and the co-

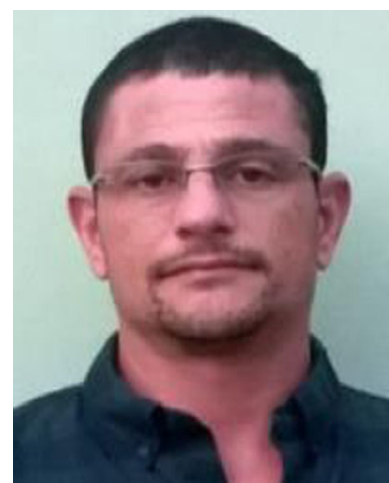

Tito Cadaval is a professor in the School of Chemistry and Food at Federal University of Rio Grande - FURG. He is a permanent member of the Technological and Environmental Chemistry postgraduation program. His research is focused on the following areas: transport phenomena, unit operations, physicochemical treatments for wastewater, and separation processes. He is an associate editor of the Environmental Science and Pollution Research.

ordinator of the Human Resources Training Program in Oil and Biofuels Processing (ANP) in UFSM. Her research interests are biomass processing for biofuel production, mathematical modeling, and optimization of chemical processes. 